ECONOMIC GROWTH CENTER

YALE UNIVERSITY

P.O. Box 208629

New Haven, CT 06520-8269

http://www.econ.yale.edu/ egcenter/

CENTER DISCUSSION PAPER NO. 933

\title{
Do Population Control Policies Induce More Human Capital Investment? Twins, Birthweight, and China's 'One Child' Policy
}

\author{
Mark R. Rosenzweig \\ Yale University \\ and \\ Junsen Zhang \\ Chinese University of Hong Kong
}

March 2006

Notes: Center Discussion Papers are preliminary materials circulated to stimulate discussions and critical comments.

The research in this paper was supported in part by NIH grant RO1 HD046144. The survey used in the paper was supported by grant CUHK4358/01H from the Research Grants Council of the Hong Kong Special Administrative Region. We also wish to thank Junjian Yi and Linda Yung for excellent research assistance.

This paper can be downloaded without charge from the Social Science Research Network electronic library at: http://ssrn.com/abstract=893056

An index to papers in the Economic Growth Center Discussion Paper Series is located at: http://www.econ.yale.edu/ egcenter/research.htm 


\title{
Do Population Control Policies Induce More Human Capital Investment? Twins, Birthweight, and China's ‘One Child’ Policy
}

Mark R. Rosenzweig and Junsen Zhang

\begin{abstract}
In this paper we use a new data set describing households with and without twin children in China to quantify the trade-off between the quality and quantity of children using the incidence of twins that for the first time takes into account effects associated with the lower birthweight and closer-spacing of twins compared to singleton births. We show that examining the effects of twinning by birth order, net of the effects stemming from the birthweight deficit of twins, can provide upper and lower bounds on the trade-off between family size and average child quality. Our estimates indicate that, at least in one area of China, an extra child at parity one or at parity two, net of birthweight effects, significantly decreases the schooling progress, the expected college enrollment, grades in school and the assessed health of all children in the family. We also show that estimates of the effects of twinning at higher parities on the outcomes of older children in prior studies do not identify family size effects but are confounded by inter-child allocation effects because of the birthweight deficit of twins. Despite the evident significant trade-off between number of children and child quality in China, however, the findings suggest that the contribution of the one-child policy in China to the development of its human capital was modest.
\end{abstract}

JEL Codes: J13, I12, I21

Keywords: Family size, Birthweight, Schooling, China 
Among the policy instruments employed in low-income countries to advance economic development are programs designed to reduce the size of families. One motivation has been that reductions in family size free up resources for investments in the human capital of the population. Supporting this idea is the influential model of Becker and Lewis (1973), which suggests that decreases in the quantity of children will induce more resources to be allocated to each child so that average child quality will increase. The challenge for empirical research has been to find sources of exogenous variation in family size to quantify the trade-off between family size and child quality implied by the Becker-Lewis quantity-quality (Q-Q) model in order to assess the efficacy of these programs for human development.

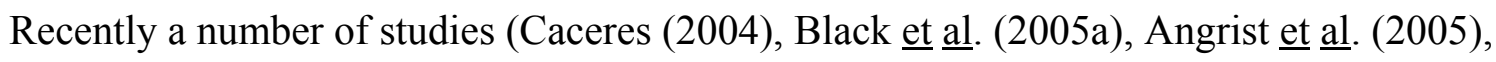
Qian (2006)) have used twinning to assess the impact of an exogenous increase in the number of children on measure of child quality. The methodology employed, based on the first uses of twins to assess responses to exogenous increases in fertility (Rosenzweig and Wolpin (1980a, 1980b)), is to estimate the effect of an extra birth at parity $\mathrm{N}$ on the quality of children at parities $\mathrm{N}-\mathrm{i}, \mathrm{i}=$ birth order, for all women who had at least $\mathrm{N}$ births. In particular, the incidence of twins at $\mathrm{N}$ is used as an instrument to predict the total of number of children born in a two-stage procedure. In all these studies measures of schooling of the parity N-i children, however, are not significantly affected or only marginally affected by whether or not those children have additional younger siblings due to twinning. The authors conclude that there is therefore little or no support for the quantity-quality trade-off implied by the Q-Q model.

These twin-based studies do not, however, examine the impact of total family size on children of parity $\mathrm{N}$ (or higher); i.e., the impact on the quality of the twins themselves is ignored. 
It is possible that the quality of the twins is lower than singleton births at $\mathrm{N}$, and that the decline in the quality for the parity $\mathrm{N}$ births is significant. If so, the basic prediction of the Q-Q model that increases in total number of children reduces average quality would not be rejected. However, the finding that the quality of the $\mathrm{N}$ - $\mathrm{i}$ children is unaffected clearly is not consistent with one basic assumption of the Q-Q model, that quality is the same for all children.

Although there is no explicit discussion of why the impact of the twins themselves is excluded from consideration, except by Caceres, presumably it is because twins are not comparable to singleton births. And, indeed, twins are different from singleton births in a very important way - the weight at birth of twins is substantially lower than that of singleton births. Figures 1 and 2 depict the distribution of birthweights from the US white population for twins and non-twins, based on the Minnesota Twins Registry (Behrman and Rosenzweig (2004) and the US National Longitudinal Survey 1979, and the birthweight distributions for twins and nontwins born in China based on the survey data we use in this paper, described below. In both countries, the average birthweight of a singleton birth is almost 30 percent higher than that of a twin, approximately a 1.5 pound difference at birth.

Recently, studies exploiting difference in birthweight between twins have shown that birthweight has significant effects on not only survival but on schooling attainment, earnings and

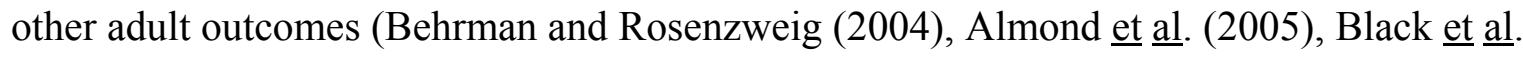
(2005b)). The birthweight deficit of twins therefore is likely to result in twins being significantly lower quality on average than non-twins, net of family size effects.

A key issue for assessing the evidence from twins studies examining the effect of twinning on non-twins is thus whether, and how, the birthweight deficit of twins affects 
investments in non-twins within the family. A number of models in the literature suggest that parents will allocate resources differentially across their children based on difference in birth endowments that affect the returns to resource investments (Becker and Tomes (1976), Hanushek (1992), Behrman et al. (1982)). If the endowments of twins are lower than those of singleton births, then twinning not only may lower average resources per child due to increases in family size, but it also may re-allocate resources differentially across children of different birth order. How parents respond to the differences in endowments between twins and non-twins within the family thus will affect inferences about the effects of twinning on non-twins. In short, if parents allocate resources within the family according to birth endowments, then the ceteris paribus effect of family size is not identified using twins unless the relationship between twinning and child endowments is taken into account.

The use of twinning as an instrument requires that all variables correlated with the incidence of twin be taken into account. Rosenzweig and Wolpin (1980a), Caceres (2004), Black et al. (2005a) and Angrist et al. (2005) control for the mother's age at birth at parity $\mathrm{N}$ because maternal age affects twinning and may be correlated as well with the outcome variables. However, none of the researchers using twinning to identify family size effects have taken into account or mentioned the birthweight deficit of twins. Caceres (2004) and other researchers who use alternative methods for identifying the causal impact of family size on child quality (e.g., Conley and Glauber (2005) and Qian (2006)), mention that spacing may have an independent effect on quality and thus that use of twins may be invalid. ${ }^{1}$ However, unlike for birthweight, no

${ }^{1}$ Angrist et al. and Conley and Glauber use the gender composition of first and secondorder births (gender sameness) as an instrument for fertility. Studies have shown that children's gender composition affects whether the parents of the children live together (Ananat and 
evidence is adduced that spacing has significant effects, net of family size, on child quality. And no researchers have gone on to show how the differential spacing of twins may affect investments to non-twin children and thus inferences about the Q-Q trade-off.

In this paper, we use unique new survey data on families with twins and with singleton births aged 7 through 18 in China to estimate the trade-off between family size and child quality based on a framework incorporating elements of the Q-Q model but allowing for heterogeneity in child endowments, birth spacing, and parents inter-child resource allocations. The survey data provide a number of advantages over the data sets that have been used to study the impact of family size on child quality. First, because of China's "one child" policy ${ }^{2}$, which is strictly enforced in the urban areas from which the survey data is from, twinning on the first birth results in one exogenous extra birth. In many developed countries twinning at low parities has a substantially smaller effect on total family size so that inferences about family size effects are less precise for the general population (all those who have one or more births). Second, in rural areas of the survey site, all families are permitted to have two children, so it is possible to replicate the parity- $\mathrm{N}$ twins methodology, at $\mathrm{N}=2$, to look at the impact of twinning on both the twins and the non-twins within the family. Again, in this population, restrictions on family size

Michael (2004), Dahl and Moretti (2004)), which may have an independent effect on children's human capital. Conley thus restricts his sample to intact couples, but does not deal with the consequent choice-based sampling problem. In the data we use in which parities only exceed two if there are twins, we cannot use this variable as an instrument. We do show, however, that gender sameness affects the allocation of resources to children net of family size effects.

${ }^{2}$ China began its one-child-per-family policy in 1979. Under this policy, each household is allowed to have only one child, although rural population are typically allowed to have a second child (but no more) in recognition of the reality in rural areas of the need for male labor (McElroy and Yang (2000)). 
are strictly enforced so that twinning at the second birth results in one extra child on average. Third, information on the birthweights of all children were obtained in the survey so that it is possible to take into account the birthweight effect of twinning and to estimate biases resulting from lack of control for birthweight. Fourth, information was elicited not only on schooling attainment but on performance in school and on parental inputs to children, including childspecific parental time and expenditures. The latter information can be used to directly estimate how birthweight endowments influence the allocation of resources across children at different birth orders. Fifth, information was also obtained on contemporaneous child anthropometrics and assessed health status, permitting estimates of family size effects on nutrition and health.

In the first part of the paper, we set out the illustrative models to show how lack of control for the lower endowments of twins biases inferences about the effects of increasing family size on child quality for children of different birth order. In particular, it is shown that the sign of the bias will differ by birth order and will depend on whether or not parents on net reinforce or compensate for variation in endowments. We also show, however, that if parents treat twins more equally than non-twins or if there are economies of scale associated with twins in part because of the closer spacing of twins that researchers have mentioned, resource allocations to twins and non-twins within the family may also differ even net of endowment effects. The effects of twinning on twins and on non-twins, however, bounds the true effect of the number of children on average child quality, with the effects on non-twins being the lower bound.

In particular, in the case in which parents reinforce differences in endowments, as found in Behrman et al. (1994) and as we find in our data, we show that the effects of twinning at 
parity $\mathrm{N}$ not accounting for endowments on singleton siblings will be a positive biased estimate of the lower-bound estimate of the effects of increasing $\mathrm{N}$ on average $\mathrm{Q}$. For the same reasons, however, estimates of twinning at parity $\mathrm{N}$ on the twins themselves will be a biased negative estimate of the upper bound effect. Controlling for endowments (birthweight), estimates of twinning at parity-N on the twins and on the older siblings provides, respectively, lower and upper bounds of the average Q-Q tradeoff, if spacing effects are important. The absence of a negative effect of twinning at the Nth birth on the quality of the parity-N-i children found in recent studies thus can be explained by our model. Because the lower birthweight of the twins is not controlled for and because parents treat twins more equally than non-twins, a re-allocation of resources from twins to the $\mathrm{N}-\mathrm{i}$ children may completely offset the negative effect of quantity on average child quality.

In the second part of the paper we describe the survey and show that twinning is indeed orthogonal to parental characteristics in our sample but that birthweight, in both the urban and rural populations, is substantially lower for twins. We also show that child gender on the first birth does not affect the probability of having a second birth in either population, and that control over family size is strictly enforced in both urban and rural areas (at different parity). In part three, we use the data to show empirically, using information on educational expenditures per child, that parents allocate more resources to children with higher birthweight, so that estimates of family size effects on non-twins induced by twinning without control for birthweight will indeed be too small.

In part four, we estimate the effects of twinning at the first birth in the urban population on schooling progress, expected schooling attainment and school grades. We show, consistent 
with parental reinforcement, that the negative effects of adding one birth due to twinning on these child quality outcomes are significantly biased negatively when birthweight is not taken into account. Controlling for birthweight, the estimates still show that the extra child reduces all four measures of child quality. The point estimates from adding one child are similar in magnitude to those obtained from high-quality studies assessing the impact of major schooling interventions and health intervention. We also find that children in two-child versus children in one-child families, net of birthweight, have lower (subjectively assessed) health, but not lower BMI, height or weight.

In the fifth section, we estimate the effects of twinning at parity two in the rural population on both parity-one and parity-two births. Again, the patterns of birthweight coefficients and the change in the parity-specific coefficients associated with twinning on the outcome measures when birthweight is included in the specification are consistent with endowment reinforcement, so that the parity-one effects are too positive when birthweight is not controlled for. The positive biases for first-born family size effects resulting from not taking into account the birthweight deficit of twins are as high as 60 percent. The estimates controlling for birthweight, however, again are consistent with a quality-quantity trade-off, in this case whether looking at first births or second births, with the difference in birth-order effects controlling for birthweight being quiet small. School progress, expected schooling attainment, math grades, literature grades, and assessed health are significantly lower for both parity-one and parity two children in the families with twins on the second birth net of birthweight differences between twins and non-twins.

In section six we use the twins data to explore economies of scale issues. There are three 
- does increasing family size increase public goods expenditures? Are there economies of scale unique to twins? And are there economies of scale associated with children being the same sex? We find evidence answering all three affirmatively. In particular, households with twins are more likely to have an internet connection, total minutes spent by parents helping each child with their homework is higher for twins than non twins, and sharing a room is substantially more likely and clothes expenditures higher per child when twins are same sex. The latter two results call into question using sex composition as an instrument for fertility, unless clothing and privacy are separable from schooling in the utility function of parents.

In the final section, we use our estimates to assess the effects of China's one-child policy on the human capital of children. Investigators have used spatial and temporal variation in the administration of the policy to assess the effects of the one-child policy on fertility. It is unlikely that such variation is orthogonal to the demand for children, and indeed in our data the fact that rural households are allowed two children and urban households one child clearly reflects governmental policy that is responsive to the differential demand for children (family labor) across sub-populations. Existing studies of the fertility effects in China derived from varying treatments thus are likely to overstate the effects of the policy. ${ }^{3}$ These estimates of the fertility

${ }^{3}$ Qian (2006) seeks to directly identify the effect of the one-child policy on child quality, in addition to employing the parity-N twins methodology, by examining how a relaxation of the one-child policy for households with a girl on the first birth affected the school enrollment of the first-born girls relative to households with one boy. Although she finds a marginally negative effect on first-borns' schooling using the twins method, the relaxation "effect" on school enrollment of first-borns is positive. She attempts to reconcile these results by conjecturing that the twins estimate overstates the negative effect. Our results show that in fact the twins results, because they do not take into account the lower endowments of twins and parental reinforcement, understate the negative effect of increased family size. Our results for parity-one twinning also show that (twin) children in two-child families are significantly worse off than single children, net of the birthweight deficit. 
effects, however, are small, suggesting, combined with the range of effects we have estimated of how reduced family size increases children's human capital, that the effects of China's one-child policy on resource investments in children in China have not played a major role in China's economic development, despite the evident trade-off between quantity and quality.

\section{The Identification of the Quantity Effect on Child Quality Using Twins}

Studies using twins to identify the effects of family size on child quality usually examine the effects of having twins on the quality of non-twins. This is done in part because of the recognition that twin births are distinct from singleton births. Estimates comparing families with and without twins might therefore, if twins are included in the comparison, only identify differences between twin and singleton births. However, all of these studies ignore decisions about resource allocations across children within the family, which has been shown to depend on the inherent or endowed characteristics of children. That twin births do differ from singleton births therefore can affect inferences about the effects of changes in the quantity of children of given endowments on child quality if the effects are obtained for children of any order. In particular, the effect of having a twin at pregnancy order $i$ on a child of order $j$ will reflect both the effect of having an extra birth and any shift in resources to or from the twins in response to the different endowments of the twins.

To fix ideas, consider first the simplest model of child quality in which a family with one child with an endowment $\mathrm{e}_{1}$ and a fixed budget constraint seeks to maximize average child quality $\mathrm{Q}$ and has $\mathrm{n}$ births at the second pregnancy, where

$$
\mathrm{Q}=\left(\mathrm{nh}_{2}{ }^{\prime}+\mathrm{h}_{1}\right) /(1+\mathrm{n}) .
$$

The quality $h_{1}$ of the order-one child is determined by the amount of resources $Z_{1}$ allocated to the 
child and by its endowment according to the production function

$$
\mathrm{h}_{1}=\mathrm{h}\left(\mathrm{Z}_{1}, \mathrm{e}_{1}\right),
$$

for which $\mathrm{h}_{\mathrm{Z1}}>0, \mathrm{~h}_{\mathrm{e} 1}>0$, and $\mathrm{h}_{\mathrm{Zlel}}>0$.

For simplicity we assume that the children produced from the second pregnancy are identical to each other but not necessarily to the first child. Each of the second-order children has an endowment $\mathrm{e}_{2}$ and their average quality $\mathrm{h}_{2}$ is produced according to the production function

$$
\mathrm{h}_{2}{ }^{\prime}=\mathrm{h}\left(\mathrm{Z}_{2}{ }^{\prime}, \mathrm{e}_{2}\right), \quad \quad \mathrm{h}_{\mathrm{Z} 2}{ }^{\prime}>0, \mathrm{~h}_{\mathrm{e} 2}>0, \text { and } \mathrm{h}_{\mathrm{Z} 2 \mathrm{e} 2}>0,
$$

where $Z_{2}^{\prime}$ is the per-child resources allocated to each of the second-pregnancy children. The budget constraint is given by

$$
n^{\alpha} Z_{2}^{\prime} p_{2}+Z_{1} p_{1}=Y,
$$

where $\mathrm{Y}=$ total income allocated to children, perhaps from a two-stage budgeting process, and the $\mathrm{p}_{\mathrm{i}}$ are the prices of the Z-goods allocated to the children of order i. Equation (4) is the standard interactive Q-Q budget constraint for the second births - with children of order 2 treated equally - except that the parameter $\alpha$ allows for economies of scale in the production of quality for the second-birth (twin) children. Twins differ from singleton births for three reasons: they have lower endowments, they are likely to be treated more equally because of their closer spacing than children born at different times, and there may be additional economies of scale in rearing them - e.g., parental reading to children. If $\alpha<1$, there are scale economies, with $Z_{2}^{\prime}$ being a pure public good for $\alpha=0$. Initially we will assume that $\alpha=1$ so that twins only differ from singletons in endowments and in being treated with equality.

Maximization of average quality entails allocating resources across the children such that marginal returns are equal across birth orders. 


$$
\mathrm{h}_{\mathrm{z} 1} \mathrm{p}_{2}=\mathrm{h}_{\mathrm{z} 2} \mathrm{p}_{1}
$$

Because of the fixity of the budget constraint, whatever the allocation of resources across children, the elasticity of average $Z$ per child with respect to $n$ is $-n /(1+n)$. If the production functions are the same across children, endowments are equal and the prices of the $\mathrm{Z}$ goods also do not differ across births $\left(\mathrm{p}_{1}=\mathrm{p}_{2}=\mathrm{p}\right)$ then all children receive equal resources, whether they are twins or not, and the elasticity of the amount of $Z_{i}$ goods with respect to the number of children $n$ born at order two is $-\mathrm{n} /(1+\mathrm{n})$ for children at any birth order i. Looking at the effect of increasing the number of children at order $\mathrm{n}$ on the allocation of resources to either order-two or order-one children provides the same elasticity.

However, if twins have lower endowments than singleton first births, the elasticity of $Z_{i}$ allocated to each child $i$ with respect to an increase in the number of children at order two, $\eta_{\mathrm{Zin}}$, is not equal to $-n /(1+n)$ and differs by birth order. In particular, if the endowments of the ordertwo children depend on the number of children due to twinning then

$$
\eta_{\text {Zin }}=\eta_{\mathrm{e} 2 \mathrm{n}} \varepsilon_{\text {Zie2 }}-\mathrm{n} /(1+\mathrm{n}),
$$

where $\eta_{\mathrm{e} 2 \mathrm{n}}=$ the elasticity of increasing $\mathrm{n}$ with respect to the endowment of the second child and $\varepsilon_{\mathrm{Zie} 2}=$ the elasticity of resources allocated to child of order $\mathrm{i}$ with respect to a change in the endowment of order-two children.

If $\mathrm{n}$ increases because of twinning, the elasticity of the order-two child endowment with respect to $\mathrm{n}, \eta_{\mathrm{e} 2 \mathrm{n}}$, is negative. And, it can be shown that in this model $\varepsilon_{\mathrm{Zie} 2}<0$ for $\mathrm{i}=1$ and $\varepsilon_{\mathrm{Zie} 2}>0$ for $\mathrm{i}=2$ - parents will allocate more of the fixed resources to children with higher endowments. ${ }^{4}$

$$
\begin{aligned}
&{ }^{4} \mathrm{dZ}_{1} / \mathrm{de}_{2}=\mathrm{h}_{\mathrm{Zze2}} /\left[\mathrm{n}^{-1} \mathrm{~h}_{\mathrm{ZzZ2}}+\mathrm{h}_{\mathrm{Z1Z1}}\right]>0, \mathrm{dZ}_{2} / \mathrm{de}_{2}=-\mathrm{h}_{\mathrm{Zze2}} /\left[\mathrm{h}_{\mathrm{ZzZ2}}+\mathrm{nh}_{\mathrm{Z1Z1}}\right]<0 \text { because } \mathrm{h}_{\mathrm{Zzee}}>0, \\
& \mathrm{~h}_{\mathrm{Z1Z1}}<0 \text { and } \mathrm{h}_{\mathrm{ZzZ2}}<0 .
\end{aligned}
$$


Thus, the relationship between the number of second-order children (as determined by twinning) and the quality of or resources devoted to the first child will underestimate the negative effect of increasing family size by $\mathrm{n}$ on average child quality. And the stronger the fall in endowments associated with twins and the larger the effect of endowments on the returns to child investments the larger will be the upward bias. Of course, for the same reason, the relationship between the number of second-birth children and the resources allocated to them will overstate the effect of family size on average child quality.

These "biases" by birth order, given by the first term in (6), arise not just due to that fact that twins have lower endowments but because the optimizing family will re-allocate resources away from the lower-endowment children to the higher-endowment child. If these re-allocations are sufficiently strong, it is possible that in families with twins on the second birth, the quality of the first child will be no less than that of first-born children in families with only a singleton second birth, as found in recent studies using twins. As can be seen, however, this difference does not represent the trade-off between average child quality and the number of children.

In the simple quality maximization model, investments in children always reinforce endowment differentials. If parents seek to balance resources across children, however, the biases due to inter-child resource allocations cannot be known a priori. However, in that case even if endowments (and prices) are the same across all children, the relationship between the number of second-birth children and the resources allocated to the first or second children will always differ, and the effect on resources allocated to the first-born will understate the effect of a change in family size on average per-child resources if parents treat twins more equally. To see this, assume that the same family maximizes the utility function 


$$
\mathrm{V}=\mathrm{V}\left(\mathrm{h}_{2}^{\prime}, \mathrm{h}_{1}\right) \text {, }
$$

where, again it is assumed that the children of order two are identical and parents only care about their average quality $\mathrm{h}_{2}{ }^{\prime}$. Parents care about the human capital distribution across children by birth order, however, and will distribute resources across the children of different birth order according to their preferences for equality and according to the differential returns to child resources. For simplicity, assume that the production functions for child quality are given by

$$
\mathrm{h}_{\mathrm{i}}=\mathrm{h}\left(\mathrm{Z}_{\mathrm{i}} \mathrm{e}_{\mathrm{i}}\right) \text {. }
$$

Maximization of (7), subject to (4) and (8), yields the first-order condition

$$
\mathrm{V}_{\mathrm{h} 2} \mathrm{~h}_{\mathrm{Z} 2} \mathrm{p}_{1} \mathrm{e}_{2} / \mathrm{n}^{\alpha}=\mathrm{V}_{\mathrm{h} 1} \mathrm{~h}_{\mathrm{Z} 1} \mathrm{p}_{2} \mathrm{e}_{1} \text {. }
$$

Parents will seek in this model to equate the marginal returns from each birth order. From (9) it can be seen that as the number of second-order children $\mathrm{n}$ increases per-child resources allocated to the order-two children are more heavily "discounted" in utility terms, leading to the reallocation of resources to the first child, with the discounting being smaller the greater the degree of scale economies; that is, as $\alpha$ approaches 0 . This is because in the absence of complete twins scale economies, allocating the same resources to the order-one child has a higher return than allocating the same resources to the order-two children, as those resources are divided among the $\mathrm{n}$ births.

In this model, the response of investments in children to a change in the number of ordertwo births via twinning differs by birth order for two reasons: the (more) equal treatment of twins and their lower endowments. More formally, conditional on endowments, the effect of an increase in the number of second-order children $\mathrm{n}$ on the resources allocated to the first child $\mathrm{Z}_{1}$ in elasticity form is 


$$
\eta_{Z 1 n} \mid e=-\alpha\left[\varepsilon_{Z 1 Y} \Phi+\eta_{Z 1 p 1}{ }^{c}\right],
$$

where $\eta_{\mathrm{ZIpl}}{ }^{\mathrm{c}}$ is the compensated own price elasticity for the resources allocated to the first child, $\varepsilon_{Z 1 Y}$ is the income elasticity, and $\Phi=n^{\alpha} Z_{2}^{\prime} p_{2} / Y$. The first term is negative, and reflects the loss in available per-child resources as the number of children increases as long as economies of scale are not complete. The second term, however, is positive. It is a price effect that arises because an increase in the number of second-parity children makes it more expensive relative to the first child to increase their average resources, again as long as $\mathrm{Z}$ does not become a pure public good. Thus the family re-allocates resources to the first child. The rise in costs per child due to an increase in the number of children, along with the assumption that (order-two) children will receive the same resources, are the essential features of the original Q-Q model. The equaltreatment assumption is plausible for twins, but it is not necessarily realistic for children of different birth orders. If so, the effect of twinning at the second birth on resources allocated to the first birth will understate the reduction in resources to children on average due to the resource constraint alone.

In contrast to the ambiguous effect of a rise in second-parity $n$ on the allocation of resources to the first child, for the second children the negative resource-constraint effect is reinforced by the reallocation effect - parents move resources $Z_{2}$ away from the (twin) children both because there are less resources available per child and because increasing their average quality is more expensive, net of any endowment differences:

$$
\eta_{\mathrm{Z} 2 \mathrm{n}} \mid \mathrm{e}=\alpha\left[-\varepsilon_{\mathrm{Z} 2 \mathrm{Y}} \Phi+\eta_{\mathrm{Z} 2 \mathrm{p} 2}{ }^{\mathrm{c}}\right] .
$$

The reduction in resources allocated to the parity-two children due to twinning at parity two will thus overstate the effect due to the resource constraint alone. 
The effect of twinning at parity two on order-one and order-two births inclusive of the effects due to the lower endowments of twins depends on whether parents reinforce or compensate for endowment differences across children. It can be shown that the elasticity of resources provided to the first child with respect to a change in the endowment of the second child can be written as

$$
\varepsilon_{\mathrm{Z} 1 \mathrm{e} 2}=\eta_{\mathrm{Z} 1 \mathrm{p} 1}{ }^{\mathrm{c}}+\varepsilon_{\mathrm{Z} 1 \mathrm{Y}} \Phi
$$

The first term in (12) is negative and the second is positive, so the resource allocation effect arising from a change in the endowment of the second-order children on the resources allocated to the first child can be either positive or negative, unlike in the first model in which parents did not care about distribution.

The total effect of twinning in the second pregnancy on the resources allocated to the first child inclusive of (i) the more equal treatment of twins due to their closer spacing compared with singletons and (ii) allocation effects due to the lower endowments of twins is thus

$$
\eta_{\mathrm{Z} 1 \mathrm{n}}=\left[\eta_{\mathrm{ne} 2}-\alpha\right]\left\{\varepsilon_{\mathrm{Z} 1 \mathrm{Y}} \Phi+\eta_{\mathrm{Z1p1}}^{\mathrm{c}}\right\}
$$

Expression (13) indicates that if parents on net reinforce endowment differences $\left(\varepsilon_{\mathrm{Zle} 2}<0\right.$ in $\left.(12)\right)$, then the following is implied by the model:

1. If the lower endowments of twins are not taken into account, the absolute value of the difference in the effect of twinning on the second pregnancy on order-two and order-one children will be greater than if the endowment differences are taken into account. That is, the understatement of the effect of increasing the quantity of children on average child quality from examining the effect of twinning in the second pregnancy on the quality of the first child will be greater than that obtained conditional on endowments ((10) versus (13)). Given reinforcement 
and a utility function in which parents care about children of different birth order, therefore not taking into account the endowment deficit of twins could lead to the quality of first-borns being no less in families with twins at the second pregnancy compared with families with two singleton births;

2. The effect of twinning on the second pregnancy on the outcomes of second-(first-) birth children provides an upper (lower) bound on the average negative effect on child outcomes of increasing family size, net of endowment differences, if parents treat twins with equality ((10) versus (11)).

If parents, however, attempt to compensate for endowment differences, the effect of second-birth twinning on either the outcomes of first-birth or second-order children can be either an over or under-estimate of the average effect of increasing child quantity on child quality. Indeed, expression (13) shows that if there are strong economies of scale in child-rearing for twins $(\alpha 60)$, the relationship between twinning on the second birth and the resources allocated to the first child will only reflect the inter-child allocation effect, which can be of any sign, rather than the quantity effect on quality. To identify the effect of anti-natalist policies on the quality (outcomes) of children using twins therefore requires information not just on child outcomes but on endowments at birth as well as information on the inputs allocated to children.

\section{The Data}

The data that we use for this study are derived from the Chinese Child Twins Survey (CCTS), the first large-scale survey based on a sample of child twins of which we are aware. The survey was designed and overseen by the authors and carried out by the Urban Survey Unit (USU) of the National Bureau of Statistics (NBS) in late 2002 and early 2003 in the Kunming 
district of China. Kunming is the capital of Yunnan province, located in the far southwestern corner of China, and is one of China's relatively undeveloped provinces. Kunming has a total population of about 5 million with about 34 percent of the population residing in officiallydesignated urban areas. The CCTS includes a probability sample of households with twins aged between 7 and 18 and a probability sample of households with non-twins in the same age range. Based on existing child questionnaires in the United States and elsewhere, the survey covered a wide range of information on children's education, including inputs of parental time and money and outcomes such as grades and schooling attainment and measures of child health, including information on each child's weight at birth and current weight and height. Respondent parents and children were separately interviewed and interviewers were instructed to separate children in different rooms, and from each other, when answering the child part of the questionnaire.

Households with child twins aged between 7 and 18 were designated as the eligible population. These were initially identified by USU according to whether children had the same birth year and month in the age interval and the same relation with the household head using data from the 2000 population census for Kunming. The addresses of the eligible households were obtained from the census office and actual child twins were then determined by household visits. For the purposes of comparison, households with non-twin children in the same age group were also surveyed. For every child twin household identified, the fourth household on the right hand side of the same block was chosen to locate a non-twin child household. (If the fourth household was not an eligible household, interviewers would continue to go to the fifth, sixth etc.). From the population census, 2300 pairs of potential twins were identified, with1694 households (3462 
children) with twins interviewed successfully. ${ }^{5}$ Of these, 1300 households had twins on the first birth and 394 households (those exempted from the one-child-per-family policy) had twins on the second birth.1693 households (1892 children) with no twins provided information in the survey.

The specifics of the one-child-per-family policy and its enforcement vary from one place to another in China. In Kunming, the one-child policy is strictly enforced in the urban area. Rural households, however, are encouraged to have one child but are exempted from the strict onechild policy (Family Planning Commission of Yunnan Province, 2003). In China, a rural-urban divide for any area is made by the administration, and there is little a household can do to take advantage of the policy difference across the boundary. Table 1 shows the distribution of family size for mothers aged 35 and over in the Kunming population, based on the CCTS data, for four groups: urban, non-exempt households with and without twins on the first birth and rural, exempt households with and without twins on the first birth. ${ }^{6}$ As can be seen, less than six percent of the non-exempt households without a twin had more than one child, while virtually all households in the non-exempt population with a twin on the first birth had only two total children. In contrast, in the exempt areas over 40 percent of households without twins had more than one child, although only 8 percent of households with a twin on the first birth, and no subsequent twins, had three children.

${ }^{5}$ The gap is due to the fact that in some households the pairs of children were not actually twins, some households had provided incorrect information on child age in the census, and some households had moved between the census date (2000) and the survey date (2002) as well as refusal and inability to locate households because of unclear addresses in mountain areas.

${ }^{6}$ Families with twins on the second birth are excluded. 
Because of strict enforcement, twinning on the first birth, but not child gender, is a powerful predictor of total family size in the urban, non-exempt population. An OLS regression of total children on twinning on the first birth for that population results in a coefficient that is almost one on a dummy variable indicating first-birth twinning, as seen in column one of Table 2. For exempt households, the same regression yields a coefficient of .66 (column two of Table 2). In contrast, for both non-exempt households and exempt households with no twins on the first birth (columns one and four), the first child being a girl does not predict total fertility. ${ }^{7}$ Only exempt households with twins on the first birth who are both girls appear to have additional children (column three), but on average less than a tenth of a child more. ${ }^{8}$

Use of twinning to assess the effects of exogenous changes in fertility on child investments and outcomes requires that parity-specific twinning be randomly distributed in the population (net of mother's age at birth). Table 3 provides descriptive statistics on the parents and children in the survey data for same four groups as used in Table 1 based on exempt status and twinning on the first birth. If twinning is random, the characteristics of the parents with and without twins on the first birth (but not necessarily the children) should be the same within each exemption category. This is confirmed in Table 3 - t-tests applied to the means of the mother's and father's schooling attainment and mother's age at the time of the survey, displayed in the

${ }^{7}$ Given that there are no additional valid instruments for fertility and that the coefficient of twinning is one in the fertility equation for the non-exempt population, there is no information gained by using twinning on the first birth as an instrument. Similarly, twinning on the second birth for the exempt population of families with two or more births has a coefficient virtually identical to one in the fertility regression (not shown).

${ }^{8} \mathrm{We}$ will see below that gender composition may not be a valid instrument for fertility, even if the gender of first-born children is not exogenous, as in many areas of China (Qian (2006). 
bottom panel of Table 3, indicate non-rejection of the hypothesis of equality within each exemption category across parents with and without twins on the first birth. However, as expected, mother's age at first birth is statistically significantly different for twins and non-twins households. ${ }^{9}$ On the other hand the policy rules evidently differ non-randomly across households. The same tests indicate that among the families without twins on the first birth, parents in the exempt and non-exempt populations have statistically significant different schooling levels and ages. ${ }^{10}$ Differences in policy rules thus cannot be used to assess the impact of fertility limitations, and comparisons based on twinning must be made within each exemption category. ${ }^{11}$

\section{Birthweight and Family Resource Allocations}

The differences across children in post-birth outcomes in the top panel of Table 3 reflect both the impact of twinning on child outcomes within groups and differences in parental characteristics across groups. Clearly, however, twinning does not merely have an effect on child outcomes by altering total fertility. Within either exemption group children who are not twins weighed almost 30 percent more at birth than did twins. ${ }^{12}$ Given that twins parents and non-twins

${ }^{9}$ The statistics for the non-exempt population are $0.72,0.71$ and 1.86 for mother's schooling, father's schooling and mother's age, respectively and 2.95 for mother's age at first birth.

${ }^{10}$ The statistics are 18.4, 17.1 and 3.70 for mother's schooling, father's schooling and mother's age, respectively and 4.42 for mother's age at first birth.

${ }^{11}$ Indeed, the less stringent fertility limitation for the "exempt" rural population is explicitly because of the higher demand for family labor and thus children.

${ }^{12}$ As seen in Figures 1 and 2 the average difference in birthweights across singleton and twins births is similar to that found by Behrman and Rosenzweig (2004) based on information obtained from the US Minnesota Twins Survey and the National Longitudinal Survey of Youth. 
parents are essentially identical, these differences in weight at birth reflect differences in nutrient intake in the womb, which have been shown to have important effects on outcomes independent of fertility effects (Behrman and Rosenzweig, 2004; Black et al. 2005b). Studies exploiting differences in birthweights within identical twin pairs identify the effects of nutrient intakes in the womb on outcomes. They do not, however, indicate how birthweight effects are mediated, if at all, by parental resource allocation behavior, which as shown in section 1 can influence the direction of differences in twins effects on outcomes between twins and non-twins within the family and can determine whether twinning effects on child outcomes are useful for identifying the effects of reducing family size on child quality.

To estimate directly whether and how parents allocate resources to children differing in birthweight, we need an input measure that is not a pure public good. The CCTS provides information on parental educational expenditures for each child. The measure includes expenses for tuition, fees for tutors, books and special classes. We estimate the following equation:

$$
\mathrm{Z}_{\mathrm{ij}}=\beta \mathrm{e}_{\mathrm{ij}}+\gamma \mathrm{e}_{\mathrm{kj}}+\mu_{\mathrm{j}}+\zeta_{\mathrm{ij}}
$$

where $Z_{\mathrm{ij}}=$ educational input for child $\mathrm{i}$ in family $\mathrm{j}, \mathrm{e}_{\mathrm{ij}}=$ child i's birthweight, $\mathrm{e}_{\mathrm{kj}}=$ child k's birthweight, $\beta=$ own endowment effect, $\gamma=$ cross endowment effect ( $=0$ if only one child), $\mu_{\mathrm{j}}=$ unobserved family effect, $\zeta_{\mathrm{ij}}=$ unobserved (to parents) child specific endowment. If parents reinforce endowment differences, then $\beta>0$ and $\gamma<0$; compensation implies $\beta<0$ and $\gamma>0$.

A major problem in identifying the effects of birthweight on parental behavior is that birthweight itself reflect prenatal inputs. Thus, for example, parents who prefer child quality may both have higher birthweight children and provide more post-birth resources to children, leading to a spurious positive relationship between weight at birth and post-birth outcomes. Thus, in (14) 
$\mu_{\mathrm{j}}$ may be correlated with the $\mathrm{e}_{\mathrm{ij}}$ and $\mathrm{e}_{\mathrm{kj}}$, so that least squares estimates of the $\beta$ and $\gamma$ parameters will be biased. One way to eliminate this source of bias is to sweep out the family fixed effect and estimate (14) based on cross-sibling differences. Differencing across i and $\mathrm{k}$ yields in $\mathrm{j}$ yields

$$
\Delta Z_{\mathrm{ij}}=(\beta-\gamma) \Delta \mathrm{e}_{\mathrm{ij}}+\Delta \zeta_{\mathrm{ij}}
$$

where $\Delta$ is the cross-sib difference operator. The within-family estimator identifies only the difference between the own and cross effect $\beta-\gamma$, which is, however, unambiguously positive for reinforcement and negative if there is compensation. Differences in the $\zeta_{\mathrm{ij}}$ may reflect parental child-specific pre-natal investments in children which may have a serially-correlated component. For example, children born early in the parents' life-cycle may have less resources than children born later, which may affect differences in resource allocations at every stage of each child's life cycle. The within-family estimator may thus not yield consistent estimates of birthweight effects on child input allocations. However, differencing across twins eliminates this source of correlation between child-specific birthweights and $\zeta_{\mathrm{ij}}$. Differences in birthweight between twins cannot be due to decisions made by parents. ${ }^{13}$

Table 4 reports least-squares, within-family and with-twin-pair estimates of the relationship between birthweight and schooling expenditures for children aged 7-14. The age range is truncated in order to minimize the proportion of school leavers in the sample. If 15 through 18-year olds were included, the expenditure input variable would be highly correlated with schooling outcomes (school attainment, enrollment), as those not in school receive little

\footnotetext{
${ }^{13}$ Genetic endowment differences between twins may be correlated with their differences in birthweight. In that case the coefficient on birthweight from the between-twins estimator cannot be interpreted as the effect purely of nutritional intake. It can be interpreted, however, as the effect of endowments, inclusive of genetics and womb intakes, on subsequent parental investments.
} 
tutoring and there is no tuition. Less than two percent of those children aged 7-14 are not in school, and these children are excluded from the sample. The included children are thus all school-goers. ${ }^{14}$ The first two columns of Table 4 report the estimate of $\beta$ for first-birth singletons in the non-exempt sample in which there are no second children. ${ }^{15}$ The estimate of the own birthweight effect on schooling expenditures is positive and statistically significant, indicating reinforcement. The second column reports estimates from a specification including parental schooling characteristics; inclusion of these reduces the estimated $\beta$ coefficient by $36 \%$, but the estimate is still statistically significant. In the third column, based on families with two singleton children in the exempt sample, the within-family estimate of the difference between the own and cross birthweight effect $\beta$ - $\gamma$ is also positive, again indicating reinforcement. ${ }^{16}$ And, the withintwin-pair estimator of the same object, reported in the last column of Table 4, estimated for all families with twins on the first birth (exempt and non-exempt), is also positive, although it is about half of the between-sib estimate. The latter point estimate indicates that a difference of about three-quarters of a kilogram in birthweight - the average difference in birthweight between twins and singletons - is associated with a reinforcing shift in schooling expenditures of about 4 percent (the average expenditure is about 500 yuan).

\section{Estimates of Child Quantity Effects Using First Birth Twins}

In this section we present estimates of how an exogenous increase in the quantity of

${ }^{14}$ The estimates are virtually identical with these children included.

${ }^{15}$ Recall that less than six percent of the households have two children.

${ }^{16}$ The between-sib estimator is consistent even if families with two singleton children are different from families with one child in the exempt sample as long as such differences are impounded in the family fixed effect $\mu_{\mathrm{j}}$. 
children affects schooling and health outcomes by comparing children in households with firstbirth twins (total family size $=2$ ) and non-twins (total family size $=1$ ) in the non-exempt sample of households. The equation we estimate is

$$
\mathrm{H}_{\mathrm{ij}}=\eta \mathrm{T}_{\mathrm{j}}+\delta \mathrm{e}_{\mathrm{ij}}+\lambda \mathrm{a}_{\mathrm{ij}}+\varepsilon_{\mathrm{ij}},
$$

where $T_{j}=1$ if the child is in a household with a first-birth twin pair, $a_{i j}$ is the age of the mother at child i's birth, and $\varepsilon_{\mathrm{ij}}$ is an error term subsuming all other determinants of the outcome $\mathrm{H}_{\mathrm{ij}}$. As shown in Rosenzweig and Wolpin (1980b), because twinning is correlated with the mother's age, and her age may be correlated with investments in children, it is necessary to control for maternal age at birth. Net of the effects of mother's age, $T_{j}$ is uncorrelated with the error term. Almost all studies using twins to estimate fertility effects have subsequently included maternal age at birth. Similarly, however, because twinning reduces birthweight which affects resource allocations, birthweight must be controlled for or $\mathrm{T}_{\mathrm{j}}$ would be correlated with the error term (containing $\mathrm{e}_{\mathrm{ij}}$ ). No studies using twins have controlled for the birthweight of the twins. The findings in Table 4 that parents reinforce birthweight differences suggest that $\mathrm{e}_{\mathrm{ij}}$ and $\varepsilon_{\mathrm{ij}}$ are positively correlated so that exclusion of birthweight from the specifications will result in a negative bias in the coefficient on the twinning variable, as parental behavior reinforces the tendency of low-birthweight children to also accumulate less post-birth human capital.

Table 5 presents the twins-first estimates for four educational outcomes. Because many of the children have not completed their schooling, information was elicited from parents on the expected schooling attainment of each of their children. Seven categories of schooling were provided in the questionnaire, conforming to the major stages in the Chinese educational system. From these data we constructed an indicator variable for whether the parents expected the child 
to attend college. ${ }^{17}$ In this urban sample, 79 percent of parents expected their child to attend college. The three other educational outcome measures used are the number of years of completed schooling of the child as of the time of the survey (schooling progress), the child's most recent math grade and the child's most recent literature grade. In all specifications the child's age and its square are included along with the mother's age at birth. Two specifications are presented, with and without inclusion of the child's birthweight.

All of the estimates, except that for the literature grade, indicate that being in a family with two twin children rather than one child reduces schooling expectations, schooling progress, and school performance significantly for the children, whether or not birthweight is controlled for. Moreover, in all cases, inclusion of birthweight as a control variable substantially reduces the estimated effect of family size as indicated by twinning, by from 20 percent for the expected college and literature grade coefficients to 15 percent for that for schooling progress, consistent with the findings that parents reinforce endowments. ${ }^{18}$ The logit point estimates indicate that the expected probability of a child attending college is 14 percent lower in families with two children, net of birthweight differences, compared with families with one child. ${ }^{19}$ In terms of schooling progress, the estimates from the specification including birthweight indicate that an extra birth, net of birthweight differences, results in a reduction in years of schooling by .23

${ }^{17}$ The categories are junior high, senior high, technical/vocational, junior college, university, post-graduate, doctoral degree. Ordered logit was used to estimate equation (16) using all seven categories. The results (available from the authors by request) were not different qualitatively from those reported in Table 5 for the college category.

${ }^{18}$ The negative coefficients on birthweight Table 5 are consistent with reinforcement and by themselves reject the hypothesis that parents fully compensate for the lower endowments of twins.

${ }^{19}$ The percentage effect is $\eta(.791)(1-.791) / .791$, where $\eta$ is the logit coefficient. 
years, or 4.1 percent.

Our estimates of the impact of fertility reduction on schooling progress are comparable to estimated schooling attainment effects associated with program interventions designed to increase schooling attainment. In particular, we can compare our estimate of the effect of reducing fertility from two children to one to estimates from three methodologically strong studies, two of which examine the impact of direct and ambitious school intervention programs. Duflo (2003) finds, using differences in differences based on Census data, that the INPRES school building program in Indonesia in the mid 1970's, which doubled the number of schools per district in five years, increased mean schooling attainment by .12 to .19 years. Schultz (2004) finds, exploiting the randomized allocation of the Mexican Progresa program, that the provision of subsidies to schooling equaling about 40 percent of adult wages increased schooling attainment by .66 years (10 percent). Finally, Miguel and Kremer find, based on a randomized intervention study, that provision of a de-worming pill increased the number of years of schooling by .14 years per treated child, inclusive of externalities. The first two of these studies did not examine school performance, but the Miguel-Kremer study could find no effect on test scores from the treatment. Our point estimates of the effects of fertility-reduction on school performance are also relatively small - a decrease in the math grade of 2.5 percent, and little effect on the literature grade from doubling family size, given weight at birth.

We can also use the CCTS to look at child health outcomes. In common with other surveys, the parents were asked to assess each child's health status in four categories - excellent, good, average, and bad. We constructed a variable indicating whether or not the child's health was assessed as excellent or good. In addition, the children's weight and height were elicited, 
from which we constructed each child's body-mass index (BMI). Table 6 presents the twins-first estimates of fertility on these health measures, again in specifications with and without the inclusion of birthweight. As for schooling attainment, the point estimates for all health measures are substantially reduced when birthweight is included. In this case, however, differences in birthweight across twins and non-twins evidently account for all of the statistically significant differences in the health assessment, height and BMI across children in families with one child and with two twin children on the first birth. However, net of birthweight, children in the twochild families weigh almost one kilogram less.

\section{Estimates of Child Quantity Effects Using Second-Birth Twins}

In this section we assess the effects of exogenously increasing the number of children at parity two on child quality by examining the impact of twinning on the second birth among households with two or more children in the exempt population. This sample, of 1709 children in exempt households with and without twins on the second birth (and no twins on the first birth), enables us to estimate the effects of having an additional child at the second birth, via twinning, on both second-birth and first-birth children. As noted, the effects of second-birth twinning on second-birth and first-birth outcomes provides upper and lower bounds, respectively, on the average impact of exogenously increasing family size net of changes in endowments, given parental reinforcement of child endowments and the relative costliness of increasing the average quality of twins compared with singletons. To tighten these bounds requires that, in addition to taking into account the relationship between maternal age at the second birth and twinning in the second pregnancy, we control for the birthweight of second births. This is because of the correlation between twinning and own birthweight. Thus we include the average birthweight for 
second births when there are twins and the birthweight of the second-born child when the second child is not a twin to take into account the effect of twinning on birthweight at parity two. Note that although it is necessary to control for the birthweight of the second births, because twinning on the second birth is neither affected by nor affects the birthweight of the first child born, in contrast to maternal age at parity two and the birthweight of parity-two children, it is not appropriate to include the (endogenous) birthweight of the first birth in the specification.

The equation we estimate is thus

$$
\mathrm{H}_{\mathrm{ij}}=\eta_{0} \mathrm{~T}_{\mathrm{j}}+\eta_{1}\left(\mathrm{~T}_{\mathrm{j}} \mathrm{x} \mathrm{F}_{\mathrm{ij}}\right)+\eta_{2} \mathrm{~F}_{\mathrm{ij}}+\delta_{1} \mathrm{e}_{2 \mathrm{j}}{ }^{*}+\delta_{2}\left(\mathrm{e}_{2 \mathrm{j}}{ }^{*} \mathrm{x} \mathrm{F}_{\mathrm{ij}}\right)+\lambda \mathrm{a}_{\mathrm{ij}}+\zeta_{\mathrm{ij}},
$$

where $T_{j}=1$ if the child is in a household with a second-birth twin pair, $F_{i j}=1$ if child $i$ is a singleton first-born, $\mathrm{e}_{2 \mathrm{j}}{ }^{*}=$ the (average) birthweight of the second-birth children (twins), and $a_{i j}=$ the mother's age at the second birth. In (17), in addition to allowing for a direct birth order effect on human capital outcomes $\eta_{2}$, in accord with models in which parents allocate resources across children according to their relative endowments the relationship between the birthweight of the second birth and child quality $\mathrm{H}$ are also allowed to differ by birth order (one or two in this case). Indeed, reinforcement implies that $\delta_{1}>0$ and $\delta_{2}<0$, so that omission of the birthweights of the second-birth children would bias upward $\eta_{1}$ (the difference in the twinning effect between first-born and second-borns) and bias downward $\eta_{0}$. However, estimation of (17) by least squares does not yield consistent estimates of $\delta_{1}, \delta_{2}$, or $\lambda$.. Second-birth birthweight and maternal age are only included in (17) so that consistent estimates are obtained of the parity-specific twinning effects $\eta_{0}$, for second-birth children, and $\eta_{0}+\eta_{1}$, for first birth children, as in expressions (10) and (11). Expressions (10) and (11) from the Q-Q model incorporating parental inter-child resource allocations implies that $\eta_{0}<0$ and $\eta_{1}>0$, net of birthweight effects. 
Table 7 reports the estimates of equation (17) for the four schooling outcome measures. As in the non-exempt sample of households, the estimates of twinning effects on the educational outcomes of twins are all negative and statistically significant, and are biased negatively (except for the completed schooling measure) when birthweight is not controlled for. The biases are again large, ranging from 13 percent for the literature grade to 35 percent for the college enrollment outcome. Comparing the own twin effects estimates in Table 5 and 7 that control for birthweight, we find that the effect of adding a child on expected college attendance, net of birthweight effects, are similar (-.11 and -.10). ${ }^{20}$ However, because only 37 percent of rural parents expected their child on average to attend college (as opposed to 79 percent in the urban population), twinning among the second-bears reduces the likelihood of college attendance by 27 percent. The coefficients on schooling progress and the math grade are also higher in absolute value than those estimated from the non-exempt sample, by approximately $50 \%$, and are double that for the literature grade in the urban sample. There is no reason to expect these coefficients to be the same across samples, as the parity of the births are different and the exempt population is rural and the non-exempt population urban. Given that most populations in low-income countries are rural and any changes in fertility are likely to operate at higher parities, the stronger negative own twin effects in the rural sample are likely to be more relevant to other developing countries.

The estimates of twins effects on twins, however, as noted, are upper bound estimates of quantity effects on average child quality. What of the estimates for the first births? For all dependent variables, the estimate of $\eta_{1}$ is positive, indicating that the effect of twinning on the

\footnotetext{
${ }^{20}$ The derivatives are based on the calculations -.372(1-.372).424 and -.791(1-.791).685 for the rural and urban populations respectively.
} 
second pregnancy is less negative on first-birth than second-birth children, consistent with the QQ framework and parental reinforcement. And, not accounting for the lower birthweight of second-birth twins biases upward the first-child coefficient for all but the schooling progress variable, leading to upward biased estimates of fertility effects for first-births, again consistent with the framework and parental reinforcement. Indeed, the patterns of signs for the birthweight coefficients are also consistent with reinforcement, as given by expression (12), except in the schooling progress equation. The upward biases in the coefficients identifying the difference between first- and second-birth effects of twinning for the expected college and grade outcomes are substantial: $35,18.5$ and 60 percent, respectively, when the birthweight of the second-births is not included in the specification.

For none of the outcomes is the fertility effect on the quality of the first births $\left(\eta_{0}+\eta_{1}\right)$ non-negative when birthweight is taken into account. Moreover, the hypothesis, controlling for birthweights, of equal effects of increasing the number of children (from two to three) on schooling outcomes for second and first births cannot be rejected except, again, for the schooling progress measure. Even for that outcome, however, the point estimate for the first child indicates that an extra child at parity two decreases schooling progress by a statistically significant .23 years for first children. Thus, the estimates indicate that an extra exogenous birth at parity two reduces the average schooling progress of the children by from .23 (4.4 percent) years to .65 years (13 percent). Interestingly, this range approximately spans the educational attainment effects of the INPRES and Progresa schooling programs, as estimated by Duflo and Schultz, respectively, and exceeds the schooling effect of de-worming. The preferred point estimates for the expected college attendance outcome suggest that an added birth at parity two 
reduces the likelihood of college attendance by 27 percent for all children, net of birthweight. And finally, even if we use the statistically insignificant point estimates of the difference between first and second-birth effects, the bounds on the estimates for the negative family size effects on school grades are very tight - between -2.6 and $-3.1(-3.2$ and 3.8 percent $)$ and -1.9 and $-2.4(-2.3$ and -2.9 percent $)$ for the math and literature grades, respectively.

The estimates in Table 8 indicate that the incidence of good or excellent health is also significantly lower for both first- and second-order births in families with three rather than two children. The point estimates for the assessed health measure indicate that, accounting for birthweight differences, the effect of increasing family size from two to three children lowers the probability of the children being in good or excellent health by from 5.2 to 11 percent. The results with respect to anthropometrics, however, are different from those for schooling measures. With and without controls for birthweight, we cannot reject the hypotheses that adding a third birth does not reduce either the weight, height or body mass index of the first child. All of the effects are on the second-order children. And these negative effects are not eliminated, except perhaps for height, when accounting for birthweight differences across twin and singleton births. Twins are almost three kilograms lighter for given age than singletons at parity two, but first-bears are no lighter whether or not they have one or two younger siblings.

\section{Public Goods, Twinning and Household Size}

The elasticities of educational outcomes with respect to family size implied by our estimates are modest, particularly in the urban sample - the urban sample estimates indicate that doubling family size at most reduces the expected probability of attending college by 14 percent and years of schooling by 4.1 percent, respectively, implying elasticities of .14 and .04 . The rural 
sample estimates, perhaps more relevant to developing countries in general, suggest, however, that decreasing family size by $50 \%$ would increase the probability of college attendance by from 6 to 27 to percent and schooling progress by from 4.6 to 13 percent, implying elasticities of educational outcomes with respect to family size of between 12 to 54 percent and 9 to 26 percent.

As suggested by the model, however, it is possible that using twins to estimate the effects of decreasing family size on parental investments in children, even accounting for endowment effects, may understate the negative impact of reducing family size on child quality because of scale economies. Scale economies may exist from increasing the number of singleton births, but they may be greater for twins because of their closer spacing. We can use the CCTS to look for evidence of both general and twin-specific economies of scale in child inputs. The gender of children may also be associated with scale economies. For example, children of the same gender may be more likely to share clothing or a room compared with children of different genders. This is important in part because gender composition has been used as an instrument for fertility, which implies that gender composition net of family size effects has no effect on the allocation of child goods.

We look at the effect of twinning on the first birth on four different child inputs using the non-exempt household sample. We modify equation (15) by adding a variable for whether or not the twins are the same gender. The first input we look at is per-child expenditures on clothing. Parents were asked how much they spend on clothing for each child. Clothing is presumably mostly a private good, but less so if children can at less cost share clothing, such as when they are of the same gender. We assume that if parents purchase an article of clothing that is worn by 
$\mathrm{N}$ children the expenditure on that item will be allocated to each child by more than $1 / \mathrm{N}$. We also look at the effect of number of children on an indicator of whether a child has his or her own room, a clearly private good. Again we would expect that children of the same gender can share a room at less cost than children of different genders. Thus, in both of these cases we would expect that adding children reduces the amount or likelihood of the private good being allocated to a child, with, however, such private goods becoming more public if children are of the same gender.

We also consider two household public goods. The first of these would appear to be especially 'public' for twins - time spent by parents providing homework assistance to each child. Such activities as reading and providing instruction have strong economies of scale - the marginal minute spent providing instruction has a higher payoff in terms of total child quality when there are two children compared with one, especially for children of the exact same age if not abilities. On the other hand, we would not expect the sex composition of children to significantly affect the return to this good. In the CCTS the children report separately the amount of minutes parents spend with them in this activity. Presumably the children do not fully discount time spent by their parents with them if that time is shared with their sibling. Finally, the second household public good we examine is whether the household is connected to the internet. This is a classic public good that would have added benefits the larger is family size; the role of gender composition is unclear, however.

Table 9 reports the estimates of the effects on the four goods of adding a child by twinning on the first birth for the non-exempt households, controlling again for mother's age at birth, the child's age and its square (not shown) and birthweight. In a second specification we 
allow the effect of increasing family size to differ by whether or not the twins are of the same gender. The estimates in the first column indicate that for child clothing, increasing the number of children marginally decreases per-child expenditures. However, this effect is evidently diluted because of scale economies associated with gender composition. When an indicator of whether the twins are the same gender is added to the specification, in column two, the effect of adding a second child almost doubles in absolute value, with, as expected twins of the same sex less deprived of clothing goods. The point estimate suggests that twins of opposite gender receive 18 percent less clothing expenditures compared with children in one-child families, but the deficit in clothing is reduced to 6.9 percent if the twins are of the same gender. Clearly gender composition matters directly for this child good.

The estimates in columns three and four also show that the effect of increasing family size on the probability of a child having his/her own room is also affected by gender composition. The point estimates indicate that adding a child that is of different gender than the first child reduces the probability that each child has his or her own room by 46 percent; the estimates also suggest that the probability each child shares a room if the twins are of the same gender is almost one. In contrast, the estimates indicate that time spent by parents assisting each child with homework, columns four and five, actually increases with the addition of one child. This is direct evidence that, at least for twins, the per-child cost of increasing the quality of children actually decreases as the quantity of children increases for one important child quality input because of scale economies. For this evidently partially public good, however, gender composition does not seem to matter. The point estimates suggest that adding a twin sibling, net of birthweight effects, increases the amount of parental homework assistance each child receives 
by 18.3 percent. Finally, the estimates in the penultimate column indicate that households with twins are also 61 percent more likely to have an internet connection compared with households that only have one child. If we add the gender composition of the twins to the specification, however, we cannot distinguish gender from quantity effects - the two variables are jointly significant at the .043 level, but each coefficient is not precisely estimated. Both are positive.

\section{Conclusion}

In this paper we have used a new data set to quantify the trade-off between the quality and quantity of children using the (random) incidence of twins that for the first time takes into account effects associated with the lower birthweight and closer-spacing of twins compared to singleton births. We show that examining the effects of twinning by birth order, net of the effects stemming from the birthweight deficit of twins, can provide upper and lower bounds on the trade-off between family size and average child quality. Our estimates indicate that, at least in one area of China, an extra child at parity one or at parity two, net of birthweight effects, significantly decreases the schooling progress, the expected college enrollment, grades in school and the assessed health of all children in the family. And the quantitative effects on schooling are at least as large as those found in methodologically sound studies assessing the impact of major school and health interventions.

We have also shown, however, that prior estimates of the effects of twinning at higher parities on the outcomes of older children do not identify family size effects but are confounded by inter-child allocation effects because of the birthweight deficit of twins. In our data, because parents evidently provide more human capital resources to children with higher endowments (reinforcement), not taking into account the birthweight deficit results in upward biased 
estimates of the trade-off between quantity and quality when such estimates are based on outcomes for the older singleton siblings of the twins, as in the existing literature. The absence of a negative effect of twinning at the Nth birth on the quality of the parity-N-i children found in a number of recent studies thus can be explained by our model and empirical results. Because the birthweight of the twins is not controlled for in those studies, the positive bias that arises due to reinforcing behavior with respect to the higher birth weight of the $\mathrm{N}$-i children may offset the negative effect of quantity on quality, as we show in our data. Our findings and those in the prior literature do, however, point to the importance of birth order effects, not taken into account in the simplest form of the Q-Q model.

We also find evidence of significant scale economies, which are also not taken into account in the simple Q-Q model. In particular we found that households with twins were significantly more likely to have an internet connection. This suggests that as electronic public goods such as televisions and computers become more prevalent, the quantity-quality trade-off may become less strong. Economies of scale were also found with respect to gender sameness siblings of the same gender were significantly more likely to share a room and had more clothing than siblings of different gender. These findings suggest that estimates identifying family size effects using gender sameness as an instrument require restrictions on preference functions.

What do our estimates imply for the effects of China's "one-child" policy on resource investments in China? To answer this question requires, in addition to our estimates, estimates of the effects of the policy on family size. Two studies have made use of the temporal and spatial variation in the administration of the policy to identify fertility effects. McElroy and Yang (2000) exploit the cross-sectional variation in the magnitude of fines for disobeying the policy. 
Qian (2006) examines the impact on fertility of relaxing the restriction on family size in some rural areas if they have a girl on the first birth. It is likely that estimates based on these policy variations are biased upward; the variation in governmental administration of the policies is likely to be responsive to differentials in the demand for children. The fact that in Kunming rural households are allowed to have two children and urban households only one clearly suggests that government policies take into account differentials in the demand for children (family labor).

The estimates from these studies of the impact of the policy on fertility are small, however - McElroy and Yang estimate that removal of the policy would increase fertility by only a third of a child. Qian finds that in families with girls, relaxation of the policy led to an average increase in family size of only .25 children. If we take the higher estimate of .33 and our upper bound estimates (but net of birthweight effects) of the effects of family size variation on measures of child human capital, we can compute upper-bound estimates of the impact of the one-child policy on human development in China. Table 10 reports these effects, which suggests that the policy at most increased schooling attainment by 4 percent, the probability of attending college by less than 9 percent, school grades by one percent, and the incidence of good or excellent health by less than four percent. Overall, despite the evident significant trade-off between number of children and child quality in China, these findings suggest that the contribution of the one-child policy in China to the development of its human capital was modest at best. 


\section{References}

Almond, Douglas, Kenneth Chay, and David Lee, “The Costs of Low Birth Weight," Quarterly Journal of Economics, August 2005, 1031-1083.

Ananat, Elizabeth O. and Guy Michaels, "The Effect of Marital Breakup on the Income and Poverty of Children," MIT Working Paper, 2004.

Angrist, Joshua D., Victor Lavy and Analia Schlosser, "New Evidence on the Causal Link Between the Quantity and Quality of Children," July 2005.

Becker, Gary S. and H.G. Lewis, "On the Interaction Between the Quantity and Quality of Children,” Journal of Political Economy 81, 2, October 1973, pp. S279-S288.

Becker, Gary S. and Nigel Tomes, "Child Endowments and the Quantity and Quality of Children,” Journal of Political Economy 84,2, October 1976, pp. S143-S162.

Behrman, Jere R., Robert A. Pollak, and Paul Taubman, "Parental Preferences and Provision for Progeny," Journal of Political Economy 90:1, February 1982, pp. 52-73.

Behrman, Jere R., Mark R. Rosenzweig and Paul Taubman, "Endowments and the Allocation of Schooling in the Family and in the Marriage Market: The Twins Experiment," Journal of Political Economy, December 1994

Behrman, Jere R. and Mark R. Rosenzweig, "Returns to Birthweight,"Review of Economics and Statistics, May 2004.

Black, Sandra E., Paul J. Devereux, and Kjell G. Salvanes, "The More the Merrier? The Effect of Family Size and Birth Order on Children's Education," Quarterly Journal of Economics 120, May 2005, pp. 669-700.

Black, Sandra E., Paul J. Devereux, and Kjell G. Salvanes, "From the Cradle to the Labor Market? The Effect of Birth Weight on Adult Outcomes," 2005

Caceres, Julio, "Impact of Family Size on Investment in Child Quality: Multiple Births as a Natural Experiment," University of Maryland, 2004.

Conley, Dalton and Rebecca Glauber, "Parental Educational Investment and Children's Academic Risk: Estimates of the Effects of Sibship Size and Birth Order from Exogenous Variation in Fertility," New York University, 2005.

Dahl, Gordon B. and Enrico Moretti, "The Demand for Sons: Evidence from Divorce, Fertility and Shotgun Marriage," NBER Working Paper No. W10281, 2004. 
Duflo, Esther, "Schooling and Labor Market Consequences of School Construction in Indonesia: Evidence from an Unusual Policy Experiment," American Economic Review, Vol. 91, No. 4, September 2001, pp. 795-813

Family Planning Commission of Yunnan Province. Regulations on Population and Family Planning in Yunnan Province. 2003.

Hanushek, Eric, "The Trade-off Between Child Quantity and Quality," The Journal of Political Economy 100, February 1992, pp. 84-117.

McElroy, Marjorie and Dennis Tao Yang, "Carrots and Sticks: Fertility Effects of China's Population Policies," American Economic Review 90, 2, Papers and Proceedings, May 2000, pp. 389-392.

Miguel, Edward and Michael Kremer, "Worms: Identifying Impacts on Education and Health in the Presence of Treatment Externalities," Econometrica 72(1), January 2004, pp. 159-217.

Qian, Nancy, "Quantity-Quality and the One Child Policy: The Positive Effect of Family Size on School Enrollment in China," January 2006.

Rosenzweig, Mark R. and Kenneth I. Wolpin, "Testing the Quantity-Quality Model of Fertility: The Use of Twins as a Natural Experiment," Econometrica, January 1980a.

Rosenzweig, Mark R. and Kenneth I. Wolpin, "Life-Cycle Labor Supply and Fertility: Causal Inferences from Household Models," Journal of Political Economy, June 1980b.

Schultz, T. Paul, "School Subsidies for the Poor: Evaluating the Mexican Progresa Poverty Program," Journal of Development Economics 74, 1, 2004, pp.199-250. 
Figure 1. Distribution of Birthweight (Kilograms):

Singleton Births in the NLSY and Twins in the Minesota Twins registry

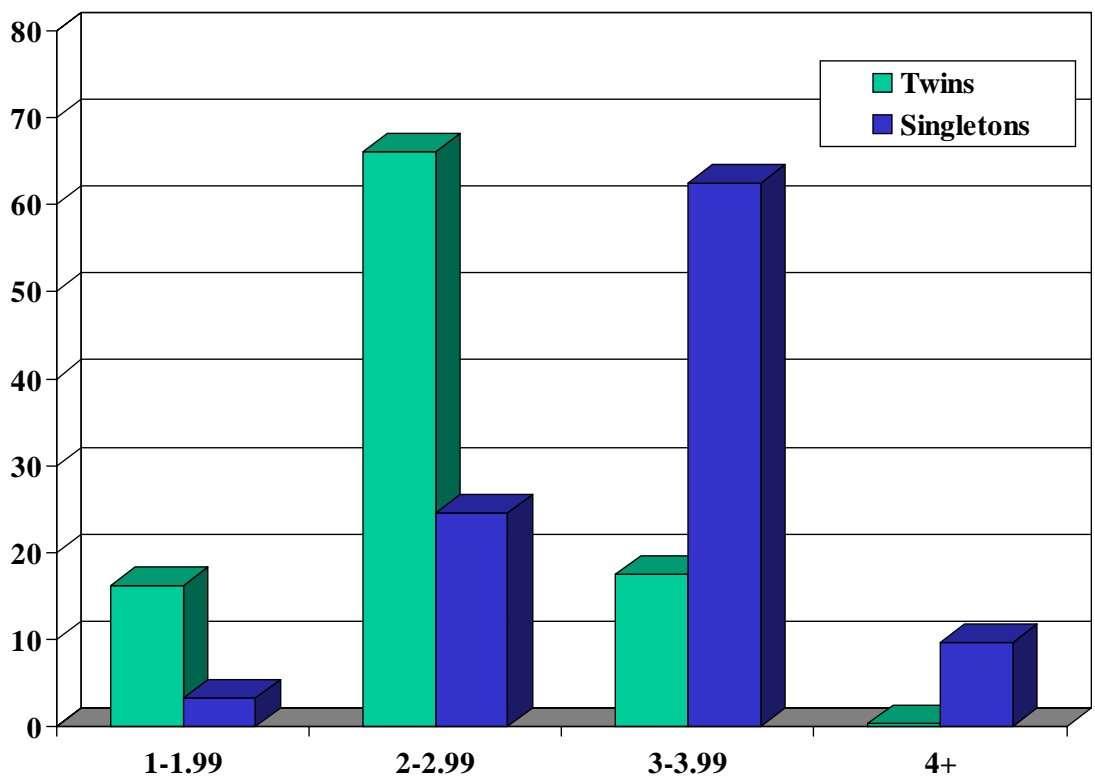

Figure 2. Distribution of Birthweight (Kilograms):

Singleton Births and Twins in Kunming, China

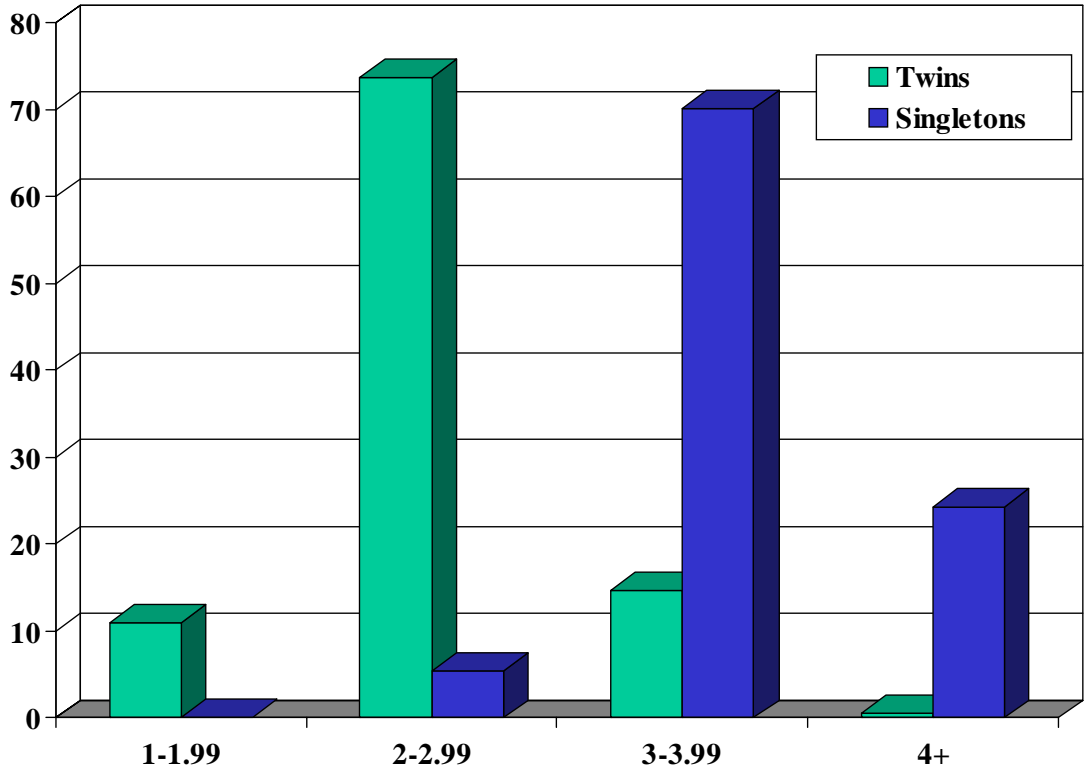


Table 1

Distribution of Fertility for Women Aged 35+, by Exemption Status and Twinning

\begin{tabular}{lcccc}
\hline \hline & $\begin{array}{c}\text { Non-exempt, no first-birth } \\
\text { twins }\end{array}$ & $\begin{array}{c}\text { Non-exempt, first-birth } \\
\text { twins }\end{array}$ & $\begin{array}{c}\text { Exempt, no first-birth } \\
\text { twins }\end{array}$ & $\begin{array}{c}\text { Exempt, first-birth } \\
\text { twins }\end{array}$ \\
\hline One child & $94.4 \%$ & 0 & 59.0 & 0 \\
Two children & 5.6 & 99.1 & 40.3 & 92.2 \\
Three children & 0 & 0.9 & 0.7 & 7.8 \\
\hline
\end{tabular}


Table 2

OLS Determinants of Children Ever Born by Exemption Status

\begin{tabular}{lcccc}
\hline \hline Sample & Non-exempt & Exempt & $\begin{array}{c}\text { Exempt, only } \\
\text { first-birth twins }\end{array}$ & $\begin{array}{c}\text { Exempt, no } \\
\text { first-birth twins }\end{array}$ \\
\hline First-birth twins & .961 & .662 & - & - \\
& $(93.5)$ & $(31.1)$ & .0689 & - \\
Both twins girls & - & - & $(2.54)$ & - \\
Both twins boys & - & - & .0134 & - \\
& & & $(0.14)$ & \\
Identical pair & - & - & -.0229 & $(0.96)$ \\
& & & - & \\
First-birth girl & -.0034 & .0291 & & $0.71)$ \\
N & $(0.33)$ & $(1.40)$ & 667 & 995 \\
\hline
\end{tabular}

All specification include the mother's age and age at first birth. 
Table 3

Descriptive Statistics by Sample: Children and Parents

\begin{tabular}{|c|c|c|c|c|}
\hline \multirow{2}{*}{$\begin{array}{l}\text { Sample } \\
\text { Fertility Rules }\end{array}$} & \multicolumn{2}{|c|}{ No Twins-First Families } & \multicolumn{2}{|c|}{ Twins-First Families } \\
\hline & Non-exempt & Exempt & Non-exempt & Exempt \\
\hline \multicolumn{5}{|c|}{ Children 7-18 } \\
\hline Birthweight & $\begin{array}{c}3.14 \\
(.486)\end{array}$ & $\begin{array}{c}3.11 \\
(.454)\end{array}$ & $\begin{array}{c}2.43 \\
(.495)\end{array}$ & $\begin{array}{c}2.46 \\
(.478)\end{array}$ \\
\hline Years of schooling & $\begin{array}{c}5.57 \\
(3.08)\end{array}$ & $\begin{array}{c}4.92 \\
(3.32)\end{array}$ & $\begin{array}{c}5.77 \\
(3.23)\end{array}$ & $\begin{array}{c}5.29 \\
(2.89)\end{array}$ \\
\hline Math grade & $\begin{array}{c}87.0 \\
(13.6)\end{array}$ & $\begin{array}{c}81.5 \\
(14.6)\end{array}$ & $\begin{array}{c}84.1 \\
(15.9)\end{array}$ & $\begin{array}{c}79.2 \\
(16.7)\end{array}$ \\
\hline Literature grade & $\begin{array}{c}87.2 \\
(11.4)\end{array}$ & $\begin{array}{c}81.6 \\
(12.2)\end{array}$ & $\begin{array}{c}85.7 \\
(12.2)\end{array}$ & $\begin{array}{c}80.0 \\
(14.0)\end{array}$ \\
\hline Weight (kg) & $\begin{array}{c}36.7 \\
(13.8)\end{array}$ & $\begin{array}{c}33.7 \\
(13.7)\end{array}$ & $\begin{array}{c}36.2 \\
(12.7)\end{array}$ & $\begin{array}{c}34.9 \\
(12.4)\end{array}$ \\
\hline Height $(\mathrm{cm})$ & $\begin{array}{l}141.1 \\
(22.6)\end{array}$ & $\begin{array}{l}132.9 \\
(25.9)\end{array}$ & $\begin{array}{l}142.8 \\
(18.5)\end{array}$ & $\begin{array}{l}138.6 \\
(19.6)\end{array}$ \\
\hline BMI & $\begin{array}{c}17.7 \\
(5.00)\end{array}$ & $\begin{array}{c}18.5 \\
(4.13)\end{array}$ & $\begin{array}{c}17.2 \\
(3.05)\end{array}$ & $\begin{array}{c}17.7 \\
(3.14)\end{array}$ \\
\hline $\mathrm{N}$ & $696(635)^{b}$ & $1421(1096)$ & $1221(1137)$ & $1424(1170)$ \\
\hline \multicolumn{5}{|c|}{ Parents } \\
\hline Mother's years of schooling & $\begin{array}{c}3.85 \\
(1.45)\end{array}$ & $\begin{array}{c}2.81 \\
(1.19)\end{array}$ & $\begin{array}{c}3.71 \\
(1.47)\end{array}$ & $\begin{array}{c}2.63 \\
(1.16)\end{array}$ \\
\hline Father's years of schooling & $\begin{array}{c}4.12 \\
(1.61)\end{array}$ & $\begin{array}{c}3.08 \\
(1.28)\end{array}$ & $\begin{array}{c}4.01 \\
(1.61)\end{array}$ & $\begin{array}{c}2.88 \\
(1.22)\end{array}$ \\
\hline Mother's age & $\begin{array}{c}36.3 \\
(4.28)\end{array}$ & $\begin{array}{c}35.3 \\
(4.55)\end{array}$ & $\begin{array}{c}37.4 \\
(4.92)\end{array}$ & $\begin{array}{c}36.6 \\
(4.98)\end{array}$ \\
\hline Mother's age at first birth & $\begin{array}{c}24.8 \\
(3.06)\end{array}$ & $\begin{array}{c}23.5 \\
(3.05)\end{array}$ & $\begin{array}{c}25.6 \\
(3.54)\end{array}$ & $\begin{array}{c}24.8 \\
(3.96)\end{array}$ \\
\hline Number of children & $\begin{array}{c}1.05 \\
(.224)\end{array}$ & $\begin{array}{c}1.40 \\
(.500)\end{array}$ & $\begin{array}{c}2.01 \\
(.114)\end{array}$ & $\begin{array}{c}2.07 \\
(.260)\end{array}$ \\
\hline $\mathrm{N}$ & 659 & 996 & 606 & 669 \\
\hline
\end{tabular}

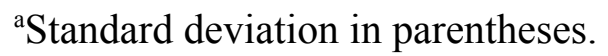

${ }^{\mathrm{b}}$ Sample size for children with field-specific grades in parentheses. 
Table 4

Effects of Birthweight on Parental Schooling Expenditures per Child: Children Aged 7-14

\begin{tabular}{|c|c|c|c|c|}
\hline Sample & \multicolumn{2}{|c|}{ First-Birth Singletons } & $\begin{array}{l}\text { First- and Second- } \\
\text { Birth Singletons }\end{array}$ & $\begin{array}{l}\text { First-Birth } \\
\text { Twins }\end{array}$ \\
\hline Estimation Procedure & \multicolumn{2}{|c|}{ OLS } & Within-Family & Within-Twin \\
\hline $\begin{array}{l}\text { Birthweight } \\
\text { (kilograms) }\end{array}$ & $\begin{array}{l}138.9 \\
(2.90)^{\mathrm{a}}\end{array}$ & $\begin{array}{l}88.6 \\
(2.01)\end{array}$ & $\begin{array}{c}59.4 \\
(1.96)\end{array}$ & $\begin{array}{l}29.4 \\
(1.95)\end{array}$ \\
\hline Age of child & $\begin{array}{c}43.1 \\
(3.43)\end{array}$ & $\begin{array}{c}56.7 \\
(4.79)\end{array}$ & $\begin{array}{c}45.2 \\
(5.69)\end{array}$ & - \\
\hline Female child & $\begin{array}{c}78.2 \\
(1.31)\end{array}$ & $\begin{array}{c}68.9 \\
(1.23)\end{array}$ & $\begin{array}{c}2.75 \\
(0.14)\end{array}$ & $\begin{array}{c}.814 \\
(0.08)\end{array}$ \\
\hline $\begin{array}{l}\text { Mother completed } \\
\text { high school }\end{array}$ & - & $\begin{array}{l}480.8 \\
(5.32)\end{array}$ & - & - \\
\hline Mother some college & - & $\begin{array}{l}773.0 \\
(4.18)\end{array}$ & - & - \\
\hline $\begin{array}{l}\text { Father completed high } \\
\text { school }\end{array}$ & - & $\begin{array}{l}161.5 \\
(2.39)\end{array}$ & - & - \\
\hline Father some college & - & $\begin{array}{l}557.3 \\
(3.93)\end{array}$ & - & - \\
\hline Intercept (First birth) & $\begin{array}{l}-242.6 \\
(1.00)\end{array}$ & $\begin{array}{l}-480.9 \\
(2.13)\end{array}$ & $\begin{array}{l}-19.6 \\
(0.75)\end{array}$ & $\begin{array}{l}-8.99 \\
(1.11)\end{array}$ \\
\hline Number of children & 1430 & 1430 & 612 & 1882 \\
\hline
\end{tabular}

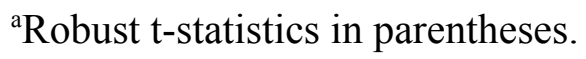


Table 5

Estimates of First-Birth Twinning on Educational Outcomes: Non-exempt Sample (N=1909)

\begin{tabular}{|c|c|c|c|c|c|c|c|c|}
\hline $\begin{array}{l}\text { Dependent } \\
\text { variable }\end{array}$ & \multicolumn{2}{|c|}{$\begin{array}{c}\text { Expected } \\
\text { College } \\
\text { Enrollment }\end{array}$} & \multicolumn{2}{|c|}{$\begin{array}{c}\text { Years of } \\
\text { Schooling } \\
\text { Completed }\end{array}$} & \multicolumn{2}{|c|}{ Math Grade } & \multicolumn{2}{|c|}{$\begin{array}{c}\text { Literature } \\
\text { Grade }\end{array}$} \\
\hline $\begin{array}{l}\text { Estimation } \\
\text { procedure }\end{array}$ & \multicolumn{2}{|c|}{ Logit } & \multicolumn{2}{|c|}{ GLS } & \multicolumn{2}{|c|}{ GLS } & \multicolumn{2}{|c|}{ GLS } \\
\hline First-birth twins & $\begin{array}{c}-.858 \\
(5.61)^{\mathrm{a}}\end{array}$ & $\begin{array}{l}-.685 \\
(3.65)\end{array}$ & $\begin{array}{l}-.276 \\
(4.85)\end{array}$ & $\begin{array}{l}-.230 \\
(3.34)\end{array}$ & $\begin{array}{l}-2.58 \\
(3.50)\end{array}$ & $\begin{array}{l}-2.12 \\
(2.27)\end{array}$ & $\begin{array}{l}-1.18 \\
(2.04)\end{array}$ & $\begin{array}{c}-.944 \\
(1.37)\end{array}$ \\
\hline Girl & $\begin{array}{c}.337 \\
(2.46)\end{array}$ & $\begin{array}{c}.372 \\
(1.28)\end{array}$ & $\begin{array}{c}.145 \\
(2.40)\end{array}$ & $\begin{array}{c}.154 \\
(2.58)\end{array}$ & $\begin{array}{l}-.132 \\
(0.18)\end{array}$ & $\begin{array}{l}-.0522 \\
(0.07)\end{array}$ & $\begin{array}{c}2.32 \\
(4.27)\end{array}$ & $\begin{array}{c}2.38 \\
(4.34)\end{array}$ \\
\hline Birthweight & - & $\begin{array}{c}.253 \\
(1.60)\end{array}$ & - & $\begin{array}{l}.0641 \\
(1.27)\end{array}$ & - & $\begin{array}{c}.652 \\
(0.76)\end{array}$ & - & $\begin{array}{c}.369 \\
(0.62)\end{array}$ \\
\hline
\end{tabular}

All specifications include the child's age, age squared and the mother's age at first birth. ${ }^{a}$ Absolute values of t-statistics in parentheses corrected for error clustering at the household level. 
Table 6

Estimates of First-Birth Twinning on Health Outcomes: Non-exempt Sample (N=1909)

\begin{tabular}{|c|c|c|c|c|c|c|c|c|}
\hline Dependent variable & \multicolumn{2}{|c|}{$\begin{array}{l}\text { Health Good or } \\
\text { Excellent }\end{array}$} & \multicolumn{2}{|c|}{ Weight (kg) } & \multicolumn{2}{|c|}{ Height $(\mathrm{cm})$} & \multicolumn{2}{|c|}{ BMI } \\
\hline Estimation & \multicolumn{2}{|c|}{ Logit } & \multicolumn{2}{|c|}{ GLS } & \multicolumn{2}{|c|}{ GLS } & \multicolumn{2}{|c|}{ GLS } \\
\hline First-birth twins & $\begin{array}{l}-.539 \\
(3.65)^{\mathrm{a}}\end{array}$ & $\begin{array}{l}-.231 \\
(1.29)\end{array}$ & $\begin{array}{l}-2.24 \\
(5.78)\end{array}$ & $\begin{array}{l}-.980 \\
(1.98)\end{array}$ & $\begin{array}{l}-1.08 \\
(1.79)\end{array}$ & $\begin{array}{l}.166 \\
(0.22)\end{array}$ & $\begin{array}{l}-.585 \\
(2.86)\end{array}$ & $\begin{array}{l}-.244 \\
(0.96)\end{array}$ \\
\hline Girl & $\begin{array}{l}.202 \\
(1.48)\end{array}$ & $\begin{array}{l}.263 \\
(1.90)\end{array}$ & $\begin{array}{l}-2.11 \\
(6.35)\end{array}$ & $\begin{array}{l}-1.84 \\
(5.38)\end{array}$ & $\begin{array}{l}-2.09 \\
(4.23)\end{array}$ & $\begin{array}{l}-1.82 \\
(3.59)\end{array}$ & $\begin{array}{l}-.232 \\
(1.36)\end{array}$ & $\begin{array}{l}-.164 \\
(0.92)\end{array}$ \\
\hline Birthweight & - & $\begin{array}{l}.352 \\
(2.90)\end{array}$ & - & $\begin{array}{c}1.81 \\
(5.14)\end{array}$ & - & $\begin{array}{c}1.80 \\
(3.58)\end{array}$ & - & $\begin{array}{c}.482 \\
(2.92)\end{array}$ \\
\hline
\end{tabular}

All specifications include the child's age, age squared and the mother's age at first birth.

${ }^{a}$ Absolute values of t-statistics in parentheses corrected for error clustering at the household level. 
Table 7

Estimates of Second-Birth Twinning on Educational Outcomes of Twins and First-birth Non-Twins:

Exempt Sample of Households with Two or More Children $(\mathrm{N}=1709)$

\begin{tabular}{|c|c|c|c|c|c|c|c|c|}
\hline \multirow{3}{*}{$\begin{array}{l}\text { Dependent variable } \\
\text { Estimation procedure } \\
\text { Second-birth twins }\end{array}$} & \multicolumn{2}{|c|}{$\begin{array}{l}\text { Expected College } \\
\text { Enrollment }\end{array}$} & \multicolumn{2}{|c|}{$\begin{array}{l}\text { Years of Schooling } \\
\text { Completed }\end{array}$} & \multicolumn{2}{|c|}{ Math Grade } & \multicolumn{2}{|c|}{ Literature Grade } \\
\hline & \multicolumn{2}{|c|}{ Logit } & \multicolumn{2}{|c|}{ GLS } & \multicolumn{2}{|c|}{ GLS } & \multicolumn{2}{|c|}{ GLS } \\
\hline & $\begin{array}{l}-.658 \\
(4.77)^{\mathrm{a}}\end{array}$ & $\begin{array}{l}-.424 \\
(2.21)\end{array}$ & $\begin{array}{l}-.626 \\
(5.48)\end{array}$ & $\begin{array}{l}-.649 \\
(5.67)\end{array}$ & $\begin{array}{l}-3.65 \\
(2.99)\end{array}$ & $\begin{array}{l}-3.10 \\
(2.44)\end{array}$ & $\begin{array}{l}-2.78 \\
(2.51)\end{array}$ & $\begin{array}{l}-2.41 \\
(2.05)\end{array}$ \\
\hline $\begin{array}{l}\text { Second-birth twins x first-birth } \\
\text { (non-twin) }\end{array}$ & $\begin{array}{c}.490 \\
(2.81)\end{array}$ & $\begin{array}{c}.327 \\
(1.78)\end{array}$ & $\begin{array}{c}.319 \\
(1.78)\end{array}$ & $\begin{array}{c}.424 \\
(2.21)\end{array}$ & $\begin{array}{c}.672 \\
(0.39)\end{array}$ & $\begin{array}{c}.548 \\
(0.31)\end{array}$ & $\begin{array}{l}1.34 \\
(0.98)\end{array}$ & $\begin{array}{c}.533 \\
(0.37)\end{array}$ \\
\hline First-birth (non-twin) & $\begin{array}{l}-.225 \\
(1.74)\end{array}$ & $\begin{array}{c}1.12 \\
(1.90)\end{array}$ & $\begin{array}{l}-.274 \\
(2.28)\end{array}$ & $\begin{array}{l}-1.11 \\
(1.83)\end{array}$ & $\begin{array}{l}-.615 \\
(0.56)\end{array}$ & $\begin{array}{c}.176 \\
(0.03)\end{array}$ & $\begin{array}{l}-.160 \\
(0.17)\end{array}$ & $\begin{array}{c}6.39 \\
(1.28)\end{array}$ \\
\hline $\begin{array}{l}\text { Mean birthweight of second } \\
\text { birth }\end{array}$ & - & $\begin{array}{l}.626 \\
(2.96)\end{array}$ & - & $\begin{array}{l}-.0616 \\
(0.42)\end{array}$ & - & $\begin{array}{l}1.42 \\
(1.07)\end{array}$ & - & $\begin{array}{c}.985 \\
(0.77)\end{array}$ \\
\hline $\begin{array}{l}\text { Mean birthweight second birth } \\
\text { x first-birth (non-twin) }\end{array}$ & - & $\begin{array}{l}-.444 \\
(2.28)\end{array}$ & - & $\begin{array}{l}.280 \\
(1.34)\end{array}$ & - & $\begin{array}{l}-.253 \\
(0.14)\end{array}$ & - & $\begin{array}{l}-2.19 \\
(1.35)\end{array}$ \\
\hline
\end{tabular}

All specifications include the child's age, age squared and sex and the mother's age at second birth.

${ }^{a}$ Absolute values of $t$-statistics in parentheses corrected for error clustering at the household level. 
Table 8

Estimates of Second-Birth Twinning on Health Outcomes of Twins and First-birth Non-Twins:

Exempt Sample of Households with Two or More Children $(\mathrm{N}=1709)$

\begin{tabular}{|c|c|c|c|c|c|c|c|c|}
\hline \multirow{3}{*}{$\begin{array}{l}\text { Dependent variable } \\
\text { Estimation procedure } \\
\text { Second-birth twins }\end{array}$} & \multicolumn{2}{|c|}{$\begin{array}{l}\text { Health Good or } \\
\text { Excellent }\end{array}$} & \multicolumn{2}{|c|}{ Weight } & \multicolumn{2}{|c|}{ Height } & \multicolumn{2}{|c|}{ BMI } \\
\hline & \multicolumn{2}{|c|}{ Logit } & \multicolumn{2}{|c|}{ GLS } & \multicolumn{2}{|c|}{ GLS } & \multicolumn{2}{|c|}{ GLS } \\
\hline & $\begin{array}{l}-.776 \\
(3.19)^{\mathrm{a}}\end{array}$ & $\begin{array}{l}-.658 \\
(2.51)\end{array}$ & $\begin{array}{l}-3.06 \\
(6.40)\end{array}$ & $\begin{array}{l}-2.93 \\
(5.80)\end{array}$ & $\begin{array}{l}-2.71 \\
(2.86)\end{array}$ & $\begin{array}{l}-1.89 \\
(1.90)\end{array}$ & $\begin{array}{l}-1.27 \\
(3.63)\end{array}$ & $\begin{array}{l}-1.58 \\
(3.85)\end{array}$ \\
\hline $\begin{array}{l}\text { Second-birth twins } x \text { first-birth } \\
\text { (non-twin) }\end{array}$ & $\begin{array}{c}.351 \\
(1.83)\end{array}$ & $\begin{array}{c}.347 \\
(1.66)\end{array}$ & $\begin{array}{c}2.84 \\
(4.85)\end{array}$ & $\begin{array}{c}2.43 \\
(3.89)\end{array}$ & $\begin{array}{l}2.55 \\
(2.62)\end{array}$ & $\begin{array}{l}2.15 \\
(2.09)\end{array}$ & $\begin{array}{c}1.35 \\
(3.99)\end{array}$ & $\begin{array}{l}1.40 \\
(3.58)\end{array}$ \\
\hline First-birth (non-twin) & $\begin{array}{l}-.417 \\
(2.25)\end{array}$ & $\begin{array}{l}-.407 \\
(0.43)\end{array}$ & $\begin{array}{l}-2.88 \\
(6.98)\end{array}$ & $\begin{array}{l}.381 \\
(0.20)\end{array}$ & $\begin{array}{l}-2.06 \\
(2.70)\end{array}$ & $\begin{array}{l}1.55 \\
(0.49)\end{array}$ & $\begin{array}{l}-1.34 \\
(4.97)\end{array}$ & $\begin{array}{l}-1.99 \\
(1.49)\end{array}$ \\
\hline $\begin{array}{l}\text { Mean birthweight of second } \\
\text { birth }\end{array}$ & - & $\begin{array}{l}.314 \\
(1.13)\end{array}$ & - & $\begin{array}{l}.348 \\
(0.63)\end{array}$ & - & $\begin{array}{c}2.24 \\
(1.84)\end{array}$ & - & $\begin{array}{c}-.860 \\
(1.85)\end{array}$ \\
\hline $\begin{array}{l}\text { Mean birthweight second birth } \\
\mathrm{x} \text { first-birth (non-twin) }\end{array}$ & - & $\begin{array}{l}-.001 \\
(0.01)\end{array}$ & - & $\begin{array}{l}-1.09 \\
(1.78)\end{array}$ & - & $\begin{array}{l}-1.20 \\
(1.18)\end{array}$ & - & $\begin{array}{l}.211 \\
(0.51)\end{array}$ \\
\hline
\end{tabular}

All specifications include the child's age, age squared and sex and the mother's age at second birth.

${ }^{a}$ Absolute values of $t$-statistics in parentheses corrected for error clustering at the household level. 
Table 9

Estimates of First-Birth Twinning on Private and Public Household Goods: Non-exempt Sample

\begin{tabular}{|c|c|c|c|c|c|c|c|c|}
\hline \multirow{3}{*}{$\begin{array}{l}\text { Dependent variable } \\
\text { Estimation procedure } \\
\text { First-birth twins }\end{array}$} & \multicolumn{2}{|c|}{$\begin{array}{l}\text { Per-child Expenditure } \\
\text { on Clothing (yuan) }\end{array}$} & \multicolumn{2}{|c|}{ Child has Own Room } & \multicolumn{2}{|c|}{$\begin{array}{l}\text { Per-Child Parental Daily } \\
\text { Time Assisting with } \\
\text { Homework (minutes) }\end{array}$} & \multicolumn{2}{|c|}{ Internet Connection } \\
\hline & \multicolumn{2}{|c|}{ GLS } & \multicolumn{2}{|c|}{ Logit } & \multicolumn{2}{|c|}{ GLS } & \multicolumn{2}{|c|}{ Logit } \\
\hline & $\begin{array}{l}-32.0 \\
(1.62)^{\mathrm{a}}\end{array}$ & $\begin{array}{l}-59.4 \\
(2.09)^{\mathrm{a}}\end{array}$ & $\begin{array}{l}-2.21 \\
(13.3)\end{array}$ & $\begin{array}{l}-1.15 \\
(5.14)\end{array}$ & $\begin{array}{c}3.81 \\
(2.79)^{\mathrm{a}}\end{array}$ & $\begin{array}{c}3.09 \\
(1.66)^{\mathrm{a}}\end{array}$ & $\begin{array}{c}.659 \\
(2.26)\end{array}$ & $\begin{array}{l}.269 \\
(0.53)\end{array}$ \\
\hline Twins same sex & - & $\begin{array}{c}36.7 \\
(1.34)\end{array}$ & - & $\begin{array}{l}-1.57 \\
(6.99)\end{array}$ & - & $\begin{array}{c}.961 \\
(0.52)\end{array}$ & - & $\begin{array}{l}.465 \\
(0.98)\end{array}$ \\
\hline Birthweight & $\begin{array}{c}18.8 \\
(1.20)\end{array}$ & $\begin{array}{c}20.1 \\
(1.28)\end{array}$ & $\begin{array}{c}.294 \\
(2.21)\end{array}$ & $\begin{array}{l}.217 \\
(1.57)\end{array}$ & $\begin{array}{c}.633 \\
(0.56)\end{array}$ & $\begin{array}{c}.476 \\
(0.42)\end{array}$ & $\begin{array}{c}.535 \\
(2.38)\end{array}$ & $\begin{array}{c}.542 \\
(2.40)\end{array}$ \\
\hline $\mathrm{N}$ & 1908 & 1908 & 1908 & 1908 & 1908 & 1908 & 1259 & 1259 \\
\hline
\end{tabular}

All specifications include the child's age, age square and the mother's age at first birth.

${ }^{a}$ Absolute values of $\mathrm{t}$-statistics in parentheses corrected for error clustering at the household level. 
Table 10

The Q-Q Trade-Off and Upper Bound Estimates of the Percentage Increase in Human Capital Measures from the One-Child Policy

\begin{tabular}{lccccc}
\hline \hline Outcome & Schooling Progress & $\begin{array}{c}\text { Proportion } \\
\text { Attending College }\end{array}$ & Math Grade & Literature Grade & $\begin{array}{c}\text { Proportion Good or } \\
\text { Excellent Health }\end{array}$ \\
\hline Q-Q Trade-Off $^{\mathrm{a}}$ & -13 & -27 & -3.8 & -2.90 & -11 \\
Policy Effect $^{\mathrm{b}}$ & 4.3 & 8.9 & 1.3 & 1.0 & 3.6 \\
\hline
\end{tabular}

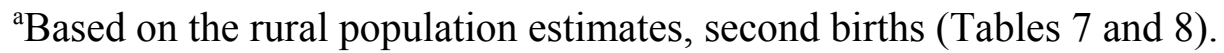

${ }^{b}$ First row $\mathrm{x}-0.33$, the McElroy-Yang policy effect on family size. 